\title{
Assessment of Pressure Transients Due to Trapped Air Compression in Rapidly Filling Combined Sewer Overflow Tunnels
}

\author{
Steven J. Wright, ${ }^{1}$ Peter R. Klaver ${ }^{2}$ and Jose G. Vasconcelos ${ }^{3}$ \\ ${ }^{1}$ University of Michigan, Ann Arbor, Michigan; ${ }^{2}$ LimnoTech Inc., Ann Arbor, Michigan; ${ }^{3}$ Auburn University, Auburn, Alabama.
}

\begin{abstract}
Numerical modeling indicates that high pressures can be expected when trapped air at the end of a pipeline is compressed as it stops a moving water column. In particular, the model results show that larger pressures are to be expected when compressed air volumes are small. Laboratory experiments where a trapped air pocket is compressed by an advancing filling front also confirm that small air volumes lead to the highest pressure rises. However, the model formulation essentially treats the moving water column as a vertical front with a trapped volume of air in front of it, an assumption that cannot be expected to hold for large diameter stormwater tunnels. The authors have been involved in the numerical modeling of rapidly filling flows in CSO storage tunnel systems. The Two-component Pressure Approach can predict the location where air can become entrapped and the associated volume, but the model framework is a single phase flow simulation and the air is not explicitly modeled. This leads to conceptual errors in the modeling of flow processes once the air becomes entrapped. The numerical model was reformulated to allowed the inclusion of the trapped air volume in the simulation in a simplified fashion. Simulations with the modified model for a specific application suggest that there are two types of flow conditions that can lead to trapped air pockets that are subsequently compressed although future investigations may define additional conditions. The simulation results suggest that only modest pressure rises should be expected in the particular application investigated and the physical explanations for this outcome are described.
\end{abstract}

\section{Introduction}

Engineering literature contains numerous reports of operational problems apparently associated with pressure transients during significant inflows into sewer and stormwater systems. Apparently is used since there are seldom physical measurements available from which the occurrence of high system pressures can be verified. Problems include structural failures of system components (Li and McCorquodale 1999; Zhou et al. 2002a) and the blowing off of manhole covers (Vasconcelos and Wright 2007a), both of which require elevated pressures. These pressures can only exist if the system is either in a surcharged state or transitioning to one. It is important to understand flow processes that may result in high system pressures in order to provide design guidance to avoid the occurrence or to provide capacity to prevent failures.

This study is part of an ongoing investigation into the effect of air on the rapid filling of sewer systems, particularly combined sewer storage tunnels. A range of experimental investigations have been performed to elucidate phenomena that may originate in sewer systems that are filling rapidly and several of of these have shown multiple ways in which large pockets of air can become entrapped in such systems during the filling process (Vasconcelos and Wright 2006) Observations have informed the required capability of numerical models to reproduce relevant phenomena and such models have been validated (e.g. Vasconcelos et al. 2007b) by comparison to experimental data, but have also been used to assist in the design of actual storage tunnel pro-jects (Lautenbach et al. 2008; Politano et al. 2007 ). Application of the numerical models to these storage tunnel projects has in turn indicated important phenomena that cannot be readily reproduced in small scale experimental systems, and the resulting feedback between experimental and numerical observations has led to an enhanced understanding of the dynamics of rapidly filling sewer systems. In this paper, this process is utilized for purposes of understanding pressure transients that can occur in rapidly filling tunnel systems with entrapped air.

\section{Background}

A number of previous studies have attempted to address pressure transients that can develop in rapidly filling sewer systems. Many of these have focused on the surges that can occur as part of the filling process. A typical combined sewer overflow deep storage tunnel accepts inflow from a number of locations, typically at the locations of previous overflows. The tunnel also typically has a

Wright, S.J., P. Klaver and J. Vasconcelos. 2016. "Assessment of Pressure Transients Due to Trapped Air Compression in Rapidly Filling Combined Sewer Overflow Tunnels." Journal of Water Management Modeling C399. doi: 10.14796/JWMM.C399.

(c) CHI 2016 www.chijournal.org ISSN: 2292-6062 
small grade towards the downstream end to facilitate drainage of the tunnel following a rainfall event. A typical filling process then leads to the tunnel becoming surcharged at the downstream end with a filling front in the form of a hydraulic bore that propagates towards the upstream end of the system. If the bore encounters a tunnel transition (reduction in upstream diameter, for example, or a vertical offset in the tunnel alignment), the bore can partially re-flect off this transition and create a strong surge which can result in increased pressures in the tunnel. Numerical models (Cardle and Song 1988; Vasconcelos et al. 2006; Leon et al. 2006; Politano et al. 2007) have been developed to model this process. Bousso and Fuamba (2012) provide a review of modeling approaches. However, a relevant observation is that the strongest surges typically occur just as the tunnel becomes initially surcharged and the resulting maximum hydraulic grade line elevation associated with the event may be even greater later in the filling process when the total storage in a deep tunnel and associated shafts is closer to the storage capacity.

One mechanism by which significant pressure rises could occur was proposed by Martin (1976). The physical system modeled involved a pipe which was partially filled with water and was initially at rest. The pipe was connected to a constant head reservoir by means of a closed valve. The pipe sloped upwards away from the reservoir such that the air in the system would be maintained at the higher elevation downstream end of the system, which was either closed or with a small diameter orifice. If the isolation valve is suddenly opened, water begins to accelerate into the pipeline from the reservoir causing the air to be compressed. Martin solved this problem by writing rigid column equations for the water motion, assumed an adiabatic or polytropic compression of the air, and either constant air mass for the closed downstream end, or mass conservation with compressible flow through the orifice, if present. Figure 1 presents numerical solutions to the closed end system of equations for two sets of conditions that differ only by the initial volume of air in the system. A relevant outcome is that strong pressure rises are predicted, especially when the initial volume of the air is small.

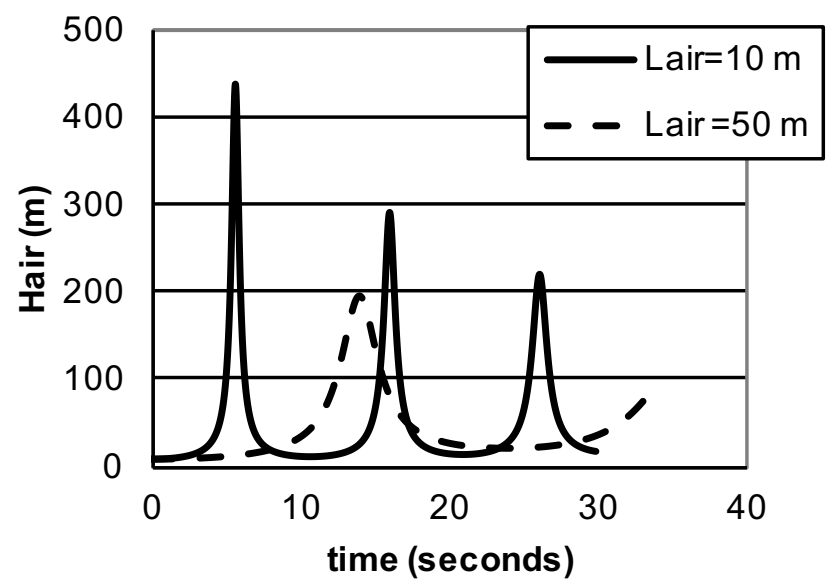

Figure 1 Numerical solutions to Martin (1976) for total pipe length $=500 \mathrm{~m}$, diameter $=0.5 \mathrm{~m}$, friction factor $=0.02$, reservoir head $=50 \mathrm{~m}$ (gauge) and initial air lengths of $10 \mathrm{~m}$ and $50 \mathrm{~m}$.
Zhou et al. (2002a) modified Martin's analysis to apply to filling flows in sewer systems. Like Martin, they assume that the filling flow is vented through a single orifice at the downstream end of the filling system. In addition to the pressurization due to air compression, they also considered the waterhammer effect of the sudden change in orifice flow rate as the last of the air is vented by the water; the large change in density from air to water makes it almost equivalent to a complete stoppage of the flow. The modeling framework is somewhat questionable since the equations assume a vertical interface between water and air. For a large diameter conduit, the fluid velocity cannot possibly be large enough to create this condition, hence the typical filling front described above proceeds from the downstream end as opposed to the upstream. In order to generate experimental data to test their model, Zhou et al. (2002b) used a pipeline with a valve in the middle that allowed a pressure differential as much as 50 atmospheres to exist prior to valve opening. These conditions are not representative of filling scenarios in sewer systems.

Vasconcelos et al. (2006) formulated a mixed flow (simultaneous presence of free surface and pressurized flow) model in order to be able to more realistically simulate flow conditions in a rapidly filling sewer, and the model was demonstrated to be robust with regards to reproducing experimental observations (e.g. Vasconcelos and Wright 2007b). However, this model framework called (the Two-component Pressure Approach, TPA) does not explicitly include the presence of the air being expelled from the filling system. This model was subsequently extended to include pressurization of air pushed ahead of a filling front in the presence of restricted ventilation (Vasconcelos and Wright 2009) and the effect on the advancing flow was successfully simulated. However, this formulation was only capable of computing the air/ water interaction if the air was a continuous phase in contact with a ventilation location. Experimental observations (Vasconcelos and Wright 2006), however, suggested that there are a large number of flow conditions that could result in the entrapment of large discrete air pockets and the behaviour of these pockets cannot be simulated with this version of the model.

The TPA framework was adapted to simulate filling processes in CSO (combined sewer overflow) storage tunnels and the resulting model, called SHAFT, was applied to applications for proposed tunnel systems, including in Washington, DC and the Thames Tideway Tunnel project in London (e.g. Lautenbach et al. 2008). In these and other applications, the air pocket entrapment process is conceptually represented since the model can accurately simulate hydraulic bores that may result in predictions in which the conduit becomes surcharged with a local void that would actually contain air. The model is thus deemed to be capable of accurately predicting locations and volumes of trapped air during the filling process so long as the air pressure remains close to atmospheric prior to the entrapment condition. However, the model breaks down after the entrapment occurrence since it does not include the air presence and instead treats the phenomenon as a void that may vanish during the filling process, even without access to a ventilation location. The vanishing of the 
void is then treated in a somewhat analogous fashion to vapour column collapse in a waterhammer analysis (Wylie and Streeter 1993, 66-9) and a large pressure transient is generated by the model. In the actual system, the compression of the air that is present may also result in a pressure transient similar to Martin (1976), but this is not related to the SHAFT predictions that model an entirely different process. The SHAFT predictions suggest a large initial pressure rise following the void collapse, after which the resulting pressure oscillations could result in predictions of pressures well below the water vapour pressure, which was considered to be a potential concern in tunnel applications since the low pressures might cause failure of the tunnel lining.

\section{Compression of Trapped Air Pockets}

Concerns for the integrity of tunnel components led to further consideration of pressure transients due to the interaction of a strong tunnel inflow with air pockets created by the filling process. Although the mechanism analysed by Martin (1976) is reasonably well understood and supported in part by the experiments by Zhou et al. (2002b), it is less clear that a hydraulic bore propagating in a partially filled conduit and trapping air in a discrete pocket that cannot be locally vented will result in similar behaviour.

\subsection{Laboratory Studies}

The phenomenon was studied with a laboratory research program; however, compromises in the experimental program were required due to the difficulty of reproducing a phenomenon expected in tunnel systems tens of kilometres long in a relatively short experimental apparatus. One such effort is reported by Wright et al. (2012) and was conducted in the apparatus indicated schematically in Figure 2.

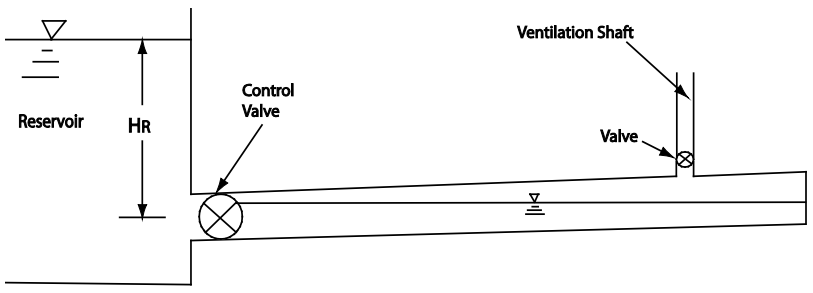

Figure 2 Experimental setup to measure air compression in arresting advancing bore initiated by opening control valve and subsequently closing valve in ventilation shaft.

The general concept is somewhat similar to the process modeled by Martin (1976) except that the conduit is laid on an almost horizontal slope so that the initial water is spread over the length of the conduit with the air distributed above the free surface. Air is vented at a location near the downstream end of the pipeline through a vertical riser with an installed valve initially open with a sufficiently large size that ventilation was relatively free. The initially closed valve at the reservoir was suddenly opened, initiating a pipe filling bore that propagated downstream forcing air ahead of it. As the bore front approached the ventilation riser, the riser valve was suddenly closed, trapping a volume of air that could be measured at the completion of the experiment. Transient pressures along the crown of the pipe were measured and exhibited an oscillatory nature that gradually damped with time. Both the maximum and minimum transient pressures were recorded and the results are discussed in Wright et al. (2012). Figure 3 indicates the maximum and minimum pressures recorded as a function of the trapped air volume. The scaling of the pressure assumes that the pressure rise can be explained as a pressure in the air pocket that would be necessary to arrest the inertia of the advancing bore. This scaling is of the form:

$$
P_{\text {max }}^{*} \text { or } P_{\text {min }}^{*}=\frac{P_{\text {max }} \text { or } P_{\text {min }}}{\rho g D \frac{A^{2}}{\left(A_{0}\left(A-A_{0}\right)\right)}}=f\left(\frac{V_{\text {air }}}{D^{3}}\right)
$$

where:

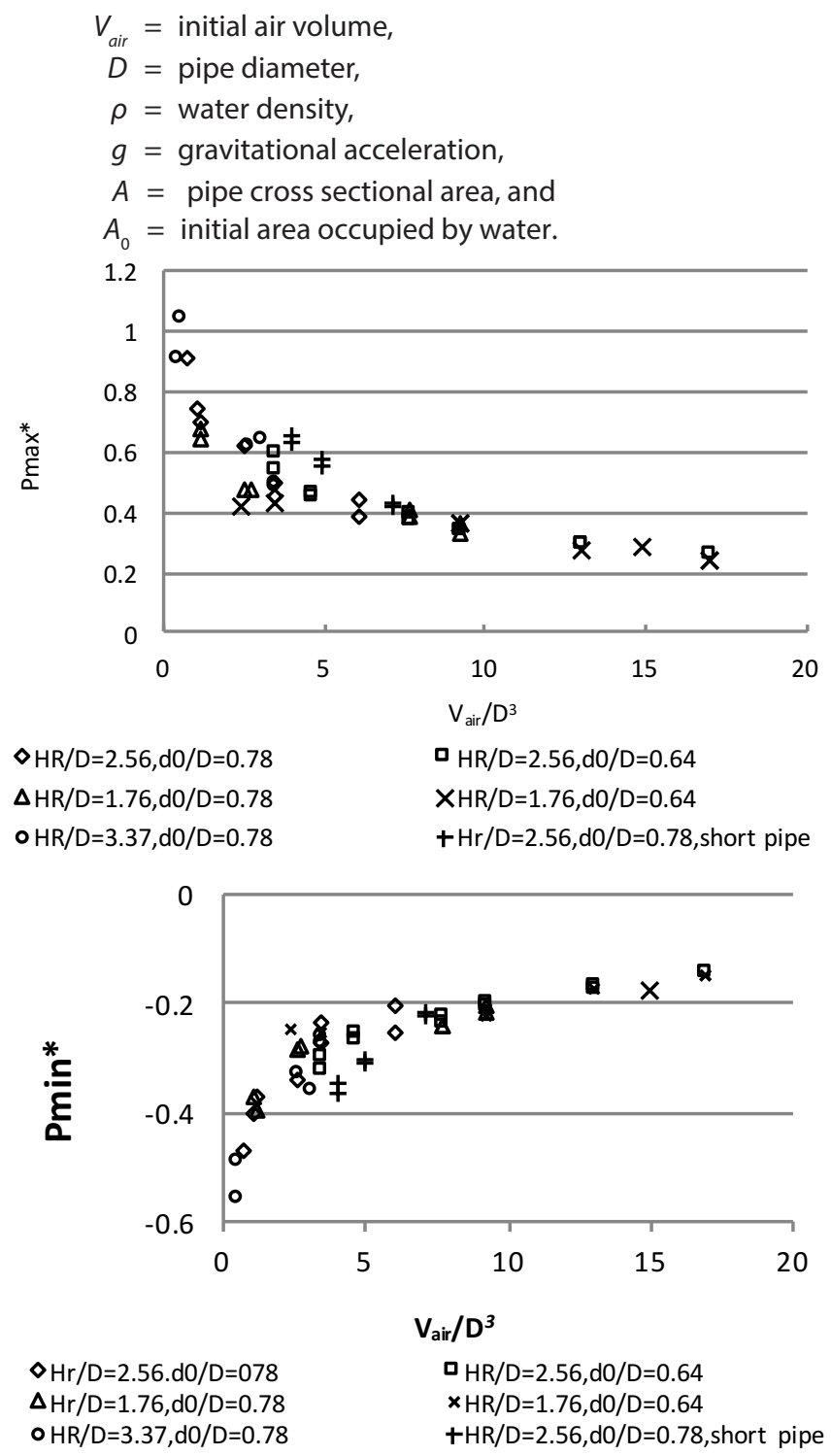

Figure 3 Maximum (upper) and minimum (lower) pressures recorded following ventilation valve closure to arrest advancing hydraulic bore; various initial water depths (d0) and reservoir heads (HR) were tested. 
Vasconcelos and Leite (2012) performed a related experimental investigation in which water was discharged from a constant head reservoir through an up-sloping pipe that discharged freely at the downstream end such that the pipe did not flow full at that end. Suddenly closing a knife gate valve at the downstream end trapped a volume of air and generated a pressure transient in the conduit. The valve could be closed completely or to some partially closed state. Again, maximum transient pressures were recorded with a similar outcome that smaller air pockets resulted in larger pressure increases. Also partial valve closures resulted in less severe transients, a not unexpected result since the flow is not completely arrested in that case. Since the experimental configuration is fundamentally different with no initial propagating bore, scaling results leading to the presentation in Figure 3 cannot be used to aggregate these experimental results.

Both these studies suggested that large pressure increases were possible, especially with small trapped air volumes, leading to conclusions that transient pressures associated with compression of trapped air may be an issue of concern, even if not predictable with a single phase model. This led to a subsequent modification of the SHAFT framework to attempt to more directly address these concerns.

\subsection{SHAFT-Air Model Framework}

As stated previously, the original SHAFT model framework is considered capable of accurately predicting the location and volume of trapped air pockets formed during the mixed flow transition so long as ventilation is adequate to prevent any significant air pressurization prior to the pocket formation. Thus, the traditional SHAFT model is appropriate up to that point in the simulation. It only becomes necessary to determine when a volume of air is surrounded by surcharged conditions with no local ventilation available. Once that condition is detected, the volume and length of the trapped air volume (corresponding to the computed void) is computed from the model output.

The air is assumed to be distributed uniformly over the determined pocket length and initially at atmospheric pressure. The pocket is effectively treated as an internal boundary condition; the air compression is treated as a polytropic process, generally with a polytropic exponent of 1.2 instead of the 1.4 required for an adiabatic process (the specific assumption has only a minor effect of the computed results). The duration of the pressure transient is considered to be small compared to the time it would take for the pocket to be transported a significant distance along the tunnel. This simplified framework is therefore not capable of resolving the entire dynamics of the pocket migration and escape at a ventilation point, but is considered capable of predicting the short term transient pressures associated with the air compression process. Additional discussion of the model is provided in Vasconcelos et al. (2015).

\section{Results and Discussion}

The original development of the SHAFT-Air model was for application to the Thames Tideway Tunnel system in London. Results will be presented for application to that system, which is indicated schematically in Figure 4 and described in Stovin et al. (2013).

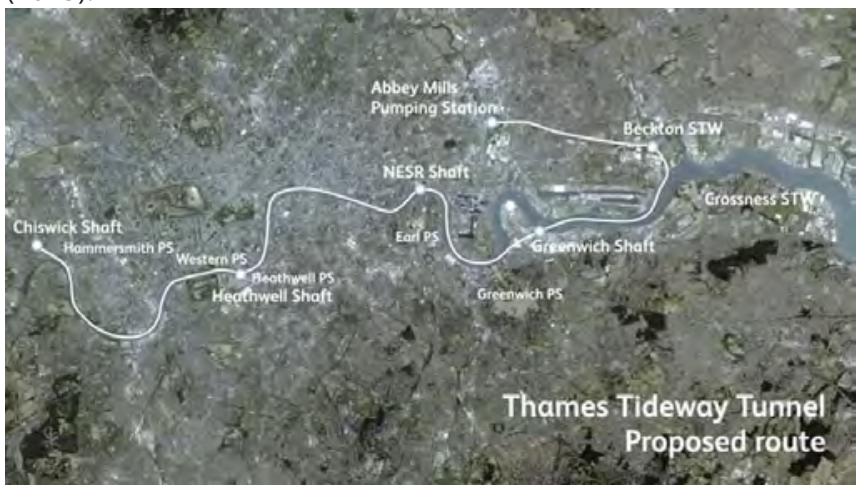

Figure 4 Schematic of Thames Tideway Tunnel system.

When completed, the system will be on the order of $25 \mathrm{~km}$ in length, with a primary diameter of $7.2 \mathrm{~m}$, and accepting inflow at the location of 34 existing CSO discharges, including through two connecting spur tunnels. The tunnel depth varies from $\sim 30 \mathrm{~m}$ to $\sim 70 \mathrm{~m}$ below grade. The tunnel slopes downward from Acton (where there is a drop in vertical alignment from a smaller diameter) to Becton. A number of different inflow scenarios were simulated and the results presented are for conditions that would lead to trapped air pockets and large hydraulic grade line elevations. In order to maintain hydraulic grade line elevations below desirable levels during major rainfall events, one design option was to control inflows by means of control gates, and proposed gate control rules are included in the presented model simulations.

\subsection{Peak Pressures}

In many applications, the peak pressures predicted by the model will be of most interest. Table 1 presents the maximum pressure predicted throughout the simulation at major system locations (e.g. pumping stations, dropshafts). In almost all cases, the SHAFT-Air simulations predicted slightly higher peak pressures than the original SHAFT model, with the increase generally being $<0.8 \mathrm{~m}$. In part, this outcome is dependent on the choice of acoustic wave speed in the SHAFT simulation. If larger acoustic wave speeds were used in the simulations, the predicted peak pressures would be generally be greater in the SHAFT predictions due to the waterhammer pressure generated following the simulated collapse of the voids represented by the entrapped air pockets. However, the pressure transient in the SHAFT-Air simulations is due to the compression of the air and effectively independent of the selected acoustic wave speed. There is also a small effect in the SHAFT-Air simulations in that the air mass is retained in the simulation and thus takes up some storage in the tunnel which will somewhat increase the predicted hydraulic grade line elevations as observed. 
Table 1 Comparison of SHAFT and SHAFT-Air predicted peak hydraulic grade lines (meters) for controlled filling scenario.

\begin{tabular}{lccc}
\hline \multicolumn{1}{c}{ Junction ID } & SHAFT & SHAFT-Air & Change \\
\hline SH01X Acton SR & 99.1 & 99.0 & -0.06 \\
CS04X TC Hammersmith & 98.6 & 98.9 & 0.32 \\
CS05X TC West Putney & 98.4 & 98.8 & 0.38 \\
CS06X TC Putney Bridge & 98.2 & 98.7 & 0.44 \\
SH24C Hurlingham & 98.2 & 98.6 & 0.35 \\
CS09X TC Falconbrook PS & 98.0 & 98.4 & 0.43 \\
CS10X TC Lots Rd & 97.8 & 98.2 & 0.44 \\
CS14X TC Ranelagh & 97.6 & 98.3 & 0.69 \\
SH11X Kirtling St & 97.5 & 98.3 & 0.83 \\
CS16X TC Heathwall SWSR & 97.5 & 98.3 & 0.84 \\
CS19X TC Brixton Clapham & 97.4 & 98.2 & 0.79 \\
CS23X TC Northumberland St & 97.5 & 98.1 & 0.59 \\
SH15X Fleet & 97.5 & 98.0 & 0.51 \\
SX17X Chambers Wharf & 97.5 & 98.0 & 0.53 \\
SX18X Northeast SR & 97.4 & 98.0 & 0.57 \\
SX23X Abbey Mills PS & 97.5 & 98.0 & 0.50 \\
Abbey Mills Shaft F & 97.5 & 98.0 & 0.50 \\
Beckton Confluence Shaft & 97.6 & 97.9 & 0.28 \\
Beckton Overflow Shaft & 97.7 & 97.9 & 0.25 \\
\hline
\end{tabular}

A major reason that the predicted peak pressures are not materially different is that the strongest transients are predicted around the time that the tunnel becomes surcharged in which case the hydraulic grade line elevation is well below grade $(30 \mathrm{~m}$ to $70 \mathrm{~m}$ )and much less than its predicted peak value later in the filling process, as indicated at one simulation location in Figure 5. Thus differences in predictions between the two models are somewhat masked by the increasing hydraulic grade line as the filling process continues. This can readily be seen in the time series predicted by the two models presented in Figure 5 at a pump station location.

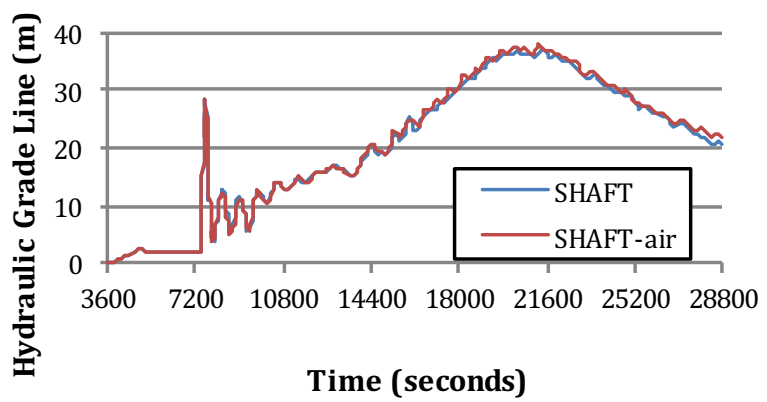

Figure 5 Predicted hydraulic grade line elevations at Greenwich Pump Station.

Figure 6 indicates model results relatively late in the filling process considerably after the initial filling transient has subsided but when the peak pressures are observed. The modeling of the trapped air changes the timing of the transient, but has only minor effects on the predicted pressures.

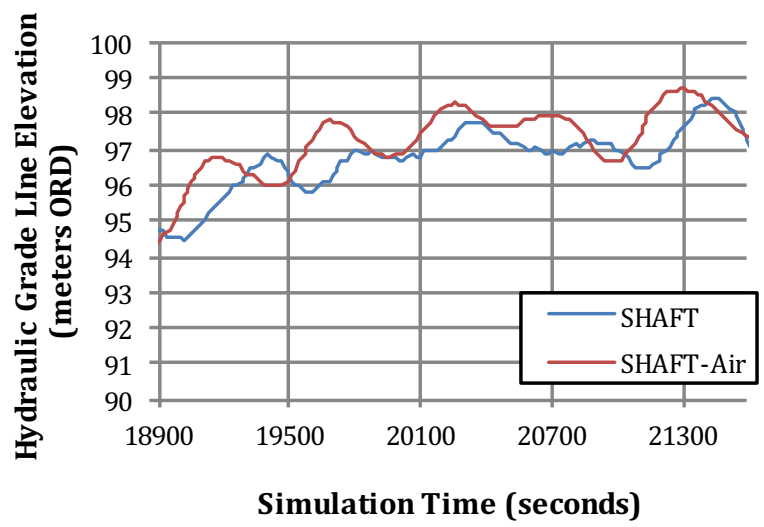

Figure 6 Predicted hydraulic grade line elevations at Greenwich Pump Station during time where maximum pressures occur.

\subsection{Minimum Pressures}

Trends for minimum pressures are different than those for maximum pressures. This is due to the fact that the pressure oscillations due to the initial surcharge events occurs on a relatively low hydraulic grade line, and differences in the simulation results immediately following this event directly determine the minimum predicted pressure. The SHAFT model commonly predicted negative (sub-atmospheric) pressures in the pressure oscillation that follows the predicted void collapse. In several instances, the predicted pressures were well below the vapour pressure of the fluid, although the model was modified to limit low pressures to vapour pressure. Figure 7 shows the minimum pressures predicted along the downstream portion of the tunnel for the two different models. The SHAFT simulation predicted a very large air pocket downstream of the Abbey Mills shaft $F$ and the void collapse generated a prediction of vapour pressure over a significant length of the tunnel. The SHAFT-Air model predicted only modest sub-atmospheric pressures, well above vapour pressure.

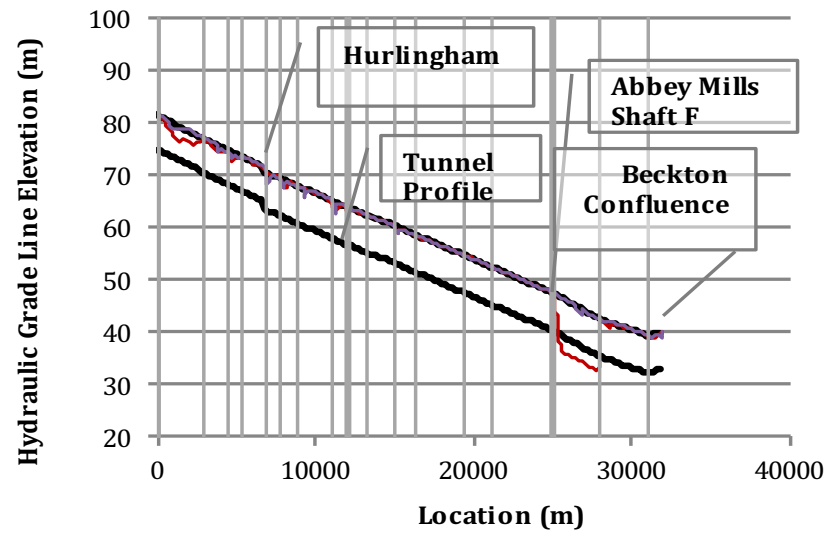




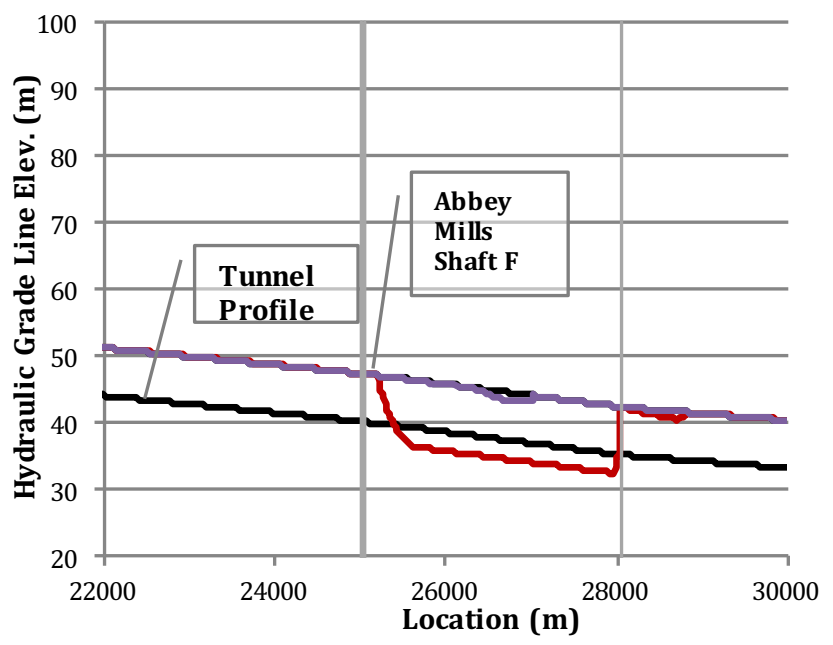

Figure 7 Predicted minimum hydraulic grade line elevations along the tunnel profile (upper: entire main tunnel; lower: expanded view near Abbey Mills shaft).

Other upstream locations in Figure 7 indicate more modest sub-atmospheric pressures predicted due to additional air entrapment events. The predictions between the two model formulations are generally in closer agreement in those locations. In a few instances, SHAFT-Air predicted slightly lower pressures than SHAFT. The differences can be explained considering the differences in the physics represented in the two models. Again, it is stressed that the SHAFT predictions are dependent on the acoustic wave speed chosen for the model. The exact choice of wave speed is uncertain since it is known (Wylie and Streeter 1993, 10) that the presence of free air in the liquid medium can reduce acoustic wave speeds down to $\sim 120 \mathrm{~m} / \mathrm{s}$; a value of about twice that was used in the simulations. If there is a very large air pocket predicted to be entrapped, the SHAFT representation as a void allows for considerable differences in velocity across the void, resulting in a large waterhammer transient as the void collapses. This effect is much reduced for a small air volume. In the case of the SHAFT-Air simulation, results such as presented in Figure 3 above indicate that smaller transient pressures are to be expected with the largest air volumes opposite to the results obtained from SHAFT. Thus, not only the magnitudes of the pressure transients are different between the two models, the conditions leading to the most severe pressure fluctuations are also different.

\subsection{Nature of the Air Entrapment Process}

A careful inspection of the SHAFT-Air predictions indicated two basic processes by which air pockets were predicted to become trapped. The first one has been discussed previously by Wright et al. $(2006,2012)$ and involves a free surface bore that reflects off a tunnel transition, closing the cross section and entrapping air. The second involves a tunnel filling bore that encounters a vertical shaft or a spur tunnel. A detailed explanation of these two conditions follows.
As briefly described previously, the typical inflow hydrograph starts to fill the tunnel slowly and the inflow magnitude increases up to a peak value, but the inflows are distributed over many inflow locations. This results in an increasing tunnel discharge in the downstream direction, in most cases, and with the small rate of filling early on, the downstream end of the tunnel becomes surcharged first. A tunnel filling bore forms and begins to propagate in the upstream direction, often with a significant pressure difference across the bore front. As the bore propagates to the upstream end of the tunnel, the strength of the bore tends to decline due to a number of effects (tunnel friction, decreasing inflow, storage at shafts and spur tunnels) and often degenerates to a free surface bore. As described by Wright et al. (2006), this bore is then followed by a gradual flow regime transition that eventually transitions to a surcharged state. The length of this transition can be simulated to be hundreds or thousands of meters, indicating a large volume of air above the free surface behind the bore. When the bore encounters a tunnel transition such as a reduction in diameter or grade change, the resulting reflection will fill the tunnel at the transition, effectively trapping all the air above the free surface behind the bore front. This situation is indicated schematically in Figure 8 (note that the slope of the conduit is exaggerated in this figure). So long as there is not a nearby shaft to vent some or all of this air, the reflected bore will compress the air pocket and produce a pressure transient. However, in general, the air volume is quite large and can cushion the bore so that pressure rises are modest.
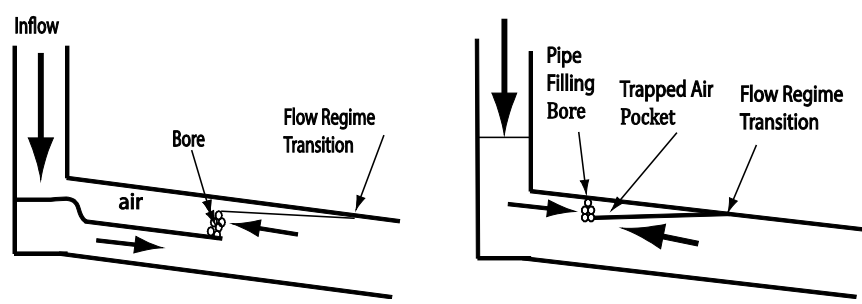

Figure 8 Schematic of air pocket entrapment due to bore reflection from channel transition.

A second case is associated with a tunnel filling bore propagating in the upstream direction and arriving at a vertical shaft or a side tunnel. The added storage can reduce the strength of the bore so that the hydraulic grade line in the shaft drops below the downstream tunnel crown. If this occurs, then air can intrude into the downstream tunnel section, creating a free surface flow with air above. At the vertical shaft, maintained inflow from upstream will eventually raise the water level above the tunnel crown and capture a pocket of air. This situation is indicated schematically in Figure 9. Once the air pocket forms, it will be forced towards the shaft where it will be vented. Notice in this situation, there is no bore inertia to arrest by compression of the air and therefore no significant pressure rise is to be expected even though the trapped air volume may be quite small. 


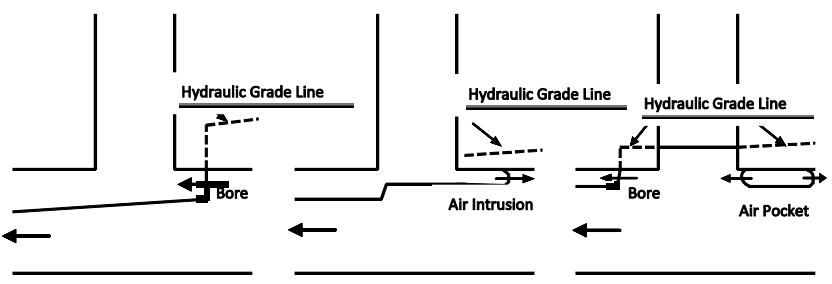

Figure 9 Schematic of air pocket entrapment due to bore arrival at vertical shaft.

Given the two scenarios for air entrapment predicted by SHAFT-Air for the proposed Thames Tideway Tunnel system, it appears that the experimental investigation previously performed by Wright et al. (2012) represents more severe conditions than would be expected in this application, especially for small air pocket volumes where the strong bore inertia would not generally be encountered. That experimental study was limited by constraints of performing tests in small scale systems where it would be difficult to reproduce the conditions described above; the experiments were conducted to produce what was considered to be an extreme transient. It should be noted that the proposed Thames Tideway Tunnel has a relatively flat grade with a somewhat uniform slope from the upstream end of the system to downstream. If other conditions exist in a sewer system, in particular if there is a high point at an intermediate location, then a wider range of flow phenomena can be expected. In instances that the authors are directly aware of in which structure damage has been experienced, geometries that facilitate air entrapment at such a location have been determined and it seems likely that a more careful application of a model such as SHAFT-Air may indicate the occurrence of more severe pressure transients.

\section{Conclusions}

Experimental observations and the simulation results from numerical models suggest that the entrapment of relatively large pockets of air is common during the rapid filling of large combined sewer storage tunnels. Single phase hydraulic models of the filling process, even when implemented to accurately predict the formation and propagation of hydraulic bores, cannot be expected to correctly capture the flow phenomena that result if the air is trapped at a location where it cannot be locally vented. Single phase models can only simulate the phenomenon as a void collapse that results in waterhammer pressure oscillations, whereas the compression of the trapped air is a fundamentally different process, albeit one that can also result in significant pressure oscillations. The single phase flow model predictions can be strongly dependent on the assumed acoustic wave speed in the model, whereas this variable would not be expected to have a major influence when air compression occurs. This paper describes a simple modification made to a single phase flow model that accounts for the compression of a trapped air pocket that is assumed not to migrate during the relatively short duration pressure oscillations that follow the entrapment process. The location and volume of the trapped air are predicted with a single phase flow model that assumes that the air can be adequately vented up to the point of entrapment. Comparisons between the original and modified models for a particular application shows that relatively significant differences occur, especially with respect to predicted minimum system pressures. The modified model that accounts for air compression suggests that for this particular application, the magnitudes of the predicted pressure oscillations are not severe, in large part because of the nature of the two flow processes that resulted in air entrapment in the numerical model application do not generally result in hydraulic bores impinging on small volumes of trapped air.

\section{References}

Bousso, S. and M. Fuamba. 2012. "Numerical Modeling of Mixed Flows in Storm Water Systems: Critical Review of Literature." Journal of Hydraulic Engineering 138 (10): 385-96.

Cardle, J. A. and C. C. S. Song. 1988. "Mathematical Modeling of Unsteady Flow in Storm Sewers." International Journal Engineering Fluid Mechanics 1 (4): 495-518.

Lautenbach, D. J., J. G. Vasconcelos, S. J. Wright, J. R. Wolfe, J. F. Cassidy, P. R. Klaver and L. R. Benson. 2008. "Analysis of Transient Surge in the Proposed District of Columbia Water and Sewer Authority Deep Tunnel System." Water Environment Federation Collection Systems: 442-68.

León, A. S., M. S. Ghidaoui, A. R. Schmidt and M. H. García. 2006. "Godunov-type Solutions for Transient Flows in Sewers." Journal of Hydraulic Engineering 132 (8): 800-13.

Li, J. and A. McCorquodale. 1999. "Modeling Mixed Flow in Storm Sewers." Journal of Hydraulic Engineering 125 (11): 1170-80.

Martin, C. S.1976. “Entrapped Air in Pipelines." Proceedings $2^{\text {nd }}$ International Conference on Pressure Surges, F2, BHRA, Bedford, UK, 15-28.

Politano, M., A. J. Odgaard and W. Klecan. 2007. "Case Study: Numerical Evaluation of Hydraulic Transients in a Combined Sewer Overflow Tunnel System." Journal of Hydraulic Engineering 133 (10): 1103-10.

Stovin, V. R., S. L. Moore, M. Wall and R. M. Ashley. 2013. “The Potential to Retrofit Sustainable Drainage Systems to Address Combined Sewer Overflow Discharges in the Thames Tideway Catchment." Water and Environment Journal 27 (2): 216-28.

Vasconcelos, J., P. Klaver and D. Lautenbach. 2015. “Flow Regime Transition Simulation Incorporating Entrapped Air Pocket Effects." Urban Water Journal 10:488-501.

Vasconcelos, J. and G. Leite. 2012. "Pressure Surges Following Sudden Air Pocket Entrapment in Storm-Water Tunnels." Journal of Hydraulic Engineering 138 (12): 1081-9.

Vasconcelos, J. G. and S. J. Wright. 2006. "Mechanisms for Air Pocket Entrapment in Stormwater Storage Tunnels." Proceedings of World Water and Environmental Resources Congress 2006, paper 40856-14275. 
Vasconcelos, J. G. and S. J. Wright 2007a. "Experimental Investigation on Surcharging of Flowing Sewers." Journal of Water Management Modeling R227-10. doi:10.14796/JWMM.R227-10.

Vasconcelos, J. G. and S. J. Wright. 2007b. “Comparison Between the Two-Component Pressure Approach and Current Transient Flow Solvers." Journal of Hydraulic Research 45 (2): 178-87.

Vasconcelos, J. G. and S. J. Wright. 2009. “Investigation of Rapid Filling of Poorly Vented Stormwater Storage Tunnels" Journal of Hydraulic Research 47 (5): 547-58.

Vasconcelos, J. G., S. J. Wright and P. L. Roe. 2006. "Improved Simulation of Flow Regime Transition in Sewers: The Two-component Pressure Approach." Journal of Hydraulic Engineering 132 (6): 553-62.

Wright S. J., C. T. Creech, J. W. Lewis and J. G. Vasconcelos. 2006. "Mechanisms of Flow Regime Transition in Rapidly Filling Stormwater Storage Tunnels." Environmental Fluid Mechanics 8:605-16.
Wright, S. J., K. V. Determan and S.M. Vargas. 2012."Pressure Transients due to Compression of Trapped Air in Rapidly Filling CSO Storage Tunnels," Journal of Water Management Modeling R245-01. doi:10.14796/JWMM.R245-01.

Wylie, E. B. and V. L. Streeter. 1993. Fluid Transients in Systems. Englewood Cliffs, NJ: Prentice-Hall Inc.

Zhou, F., F. E. Hicks and P. M. Steffler. 2002a. "Transient Flow in a Rapidly Filling Horizontal Pipe Containing Trapped Air." Journal of Hydraulic Engineering 128 (6): 625-34.

Zhou, F., F. E. Hicks and P. M. Steffler. 2002b. "Observations of Air-Water Interaction in a Rapidly Filling Horizontal Pipe." Journal of Hydraulic Engineering 128 (6): 635-9. 